4. Galve, E., Ordi, J., Barquinero, J., Evangelista, A., Vilardell, M. \& Soler-Soler, J. Valvular heart disease in the primary antiphospholipid syndrome. Ann Intern Med 1992, 116: 293-298.

5. Canoso, R.T. \& Sise, H.S. Chlorpromazine induced lupus anticoagulant and associated immunological abnormalities. Am J Hematol 1982, 13: 121-129.

6. Anon. Lupus anticoagulant. Lancet 1984, 389: 1157-1158.

7. Elias, M. \& Eldor, A. Thromboembolism in patients with the 'lupus'-type circulating anticoagulant. Arch Intern Med 1984, 144: 510-515.

8. Weiner, H.N., Vardinon, N. \& Yust, I. Platelet antibody binding and spontaneous aggregation in 21 lupus anticoagulant patients. Vox Sang 1991, 61: 111-121.
9. Harris, E.N., Asherson, R.A., Gharavi, A.E., Morgan, S.H. Derve, G. \& Hughes, G.R.V. Thrombocytopenia in SLE andd related autoimmune disorders: association with anticardiolipin antibodies. Br J Haematol 1985, 59: 227-230.

10. Dickinson, C.J. \& Martin, J.F. Megakaryocytes and platelet: clumps as the cause of finger clubbing. Lancet 1987, 573: 1434-1435.

11. Fox, S.B., Day, C.A. \& Gatter, K.C. Association between platelet microthrombi and finger clubbing. Lancet 1991, 336 $\overline{\frac{\pi}{5}}$ 313-314.

\title{
The development of spontaneous colo-umbilical fistula
}

\author{
John B. Pracyk, Stephen G. Pollard and Sir Roy Y. Calne
}

Department of Surgery, University of Cambridge, Level 9, Addenbrooke's Hospital, Hills Road, Cambridgecs $C B 22 Q Q, U K$

\begin{abstract}
Summary: A patient with colo-umbilical fistula is reported. This presentation is unique because io documents the development of a fistula from a colonic diverticulum. Sigmoid colectomy was undertakei successfully.
\end{abstract}

\section{Introduction}

Entero-umbilical fistulas are rare $^{1}$ and in most cases there is a predisposing cause. Here we describe a case of a fistula that developed from a diverticulum of the sigmoid colon that discharged through the umbilicus. To our knowledge, a spontaneous colo-umbilical fistula has not been described previously. We discuss the pathophysiology and the rationale for surgical management.

\section{Case report}

A 76 year old male retired engineer was admitted in September 1992 with a faecal discharge from the umbilicus. Two years previously, an asymptomatic abdominal mass palpable below the umbilicus had been identified on routine physical examination by his general practitioner. Computerized tomography (CT) studies of the abdomen had revealed that the mass arose from the pelvis, lying caudal to the umbilicus and anterior to the sigmoid colon. Although this structure was filled with air, open communication with the lumen of the sigmoid colon could not be demonstrated on CT scan. A

Correspondence: Stephen G. Pollard, F.R.C.S.

Accepted: 11 January 1993 provisional diagnosis of a giant colonic diver ticulum was made and a conservative approach $\mathbb{\complement}$ adopted since the patient was asymptomatic and in poor general health secondary to diabetes and a3 previous cerebral infarct. A CT scan some 18 months later revealed an air-filled sinus that now communicated with the umbilicus, yet the patiento remained asymptomatic (Figure 1). Five to 6 weeks 3 . prior to admission, the patient experienced constipation with intermittent diarrhoea. This coin $\frac{3}{6}$ cided with the onset of a faecal discharge from hiso umbilicus.

On examination he was afebrile and welle nourished. The abdomen was soft, non-tender, and with a fixed palpable mass in the hypogastrium and? left iliac fossa. Haematological and biochemistryn studies were within normal limits. A barium enema study demonstrated a $7 \mathrm{~cm}$ stricture of the sigmoido colon with a small perforation emptying into the cavity, identified previously by CT scan (Figure 2)

Laparotomy was performed through a midlineo incision and a large cavity in the preperitoneato space was entered. This was not a colonic diver - ? ticulum and was lined with granulation tissue. It communicated with the umbilicus and a large perforation in the sigmoid colon. A sigmoid colec- 
tomy with primary anastomosis was performed and a drain placed in the cavity. Histopathology revealed that the serosal surfaces of the sigmoid

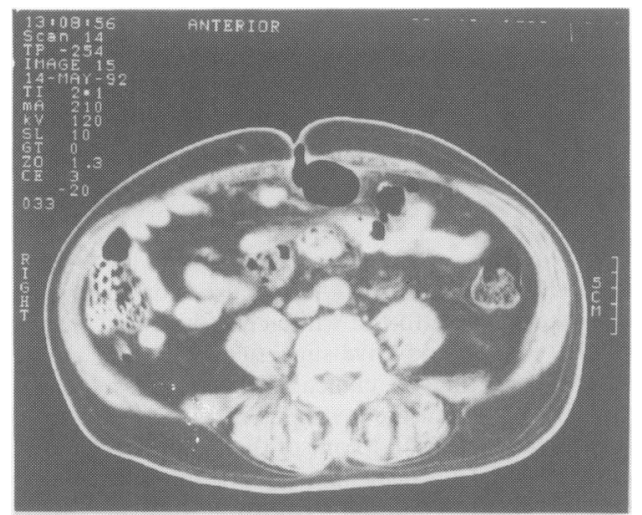

Figure 1 CT scan of the abdomen demonstrating extension of the cavity into the umbilicus.

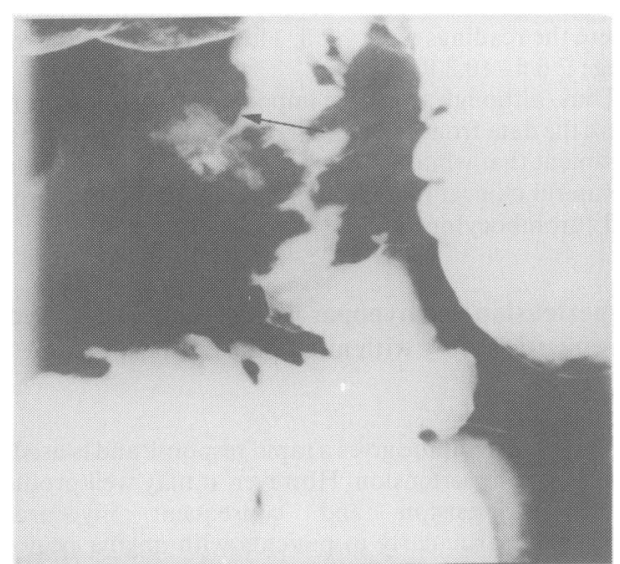

Figure 2 Barium enema illustrating a stricture in the sigmoid colon and a focal perforation (arrow) with barium extravasation. Diverticular disease is also evident.

\section{References}

1. Burchell, M.C. Spontaneous umbilical fistula in Crohn's disease. Report of a case. Dis Colon Rectum 1989, 32: 621-623.

2. Sternquist, J.C., Burbrick, M.P. \& Hitchcock, C.R. Enterocutaneous fistulas. Dis Colon Rectum 1978, 21: 578-581.

3. Garay, G. \& Mihalyi, L. Pseudomyxoma peritonea and umbilical fistula arising through an omphalocyst. Radiologia Clinica et Biologica 1968, 37: 123-127.

4. Bocchi, G. \& Sirica, S. Vesico-umbilical fistula due to the perviousness of the urachus. Quaderni Di Radiologia 1965, 30: 85-92.

5. Ubhi, C.S. \& Wenham, P.W. Spontaneous enterumbilical fistula. $B r$ Med J 1984, 57: 1034-1036.

6. Tsvetkov, T. \& Poriazov, K. A case of utero-umbilical fistula following caesarean section diagnosed at uterine perforation during curettage. Akusherstvo I Ginekologiia 1973, 12: 263-264.

7. Schreck, W.R. \& Campbell, W.A. The relation of bladder outlet obstruction to urinary-umbilical fistula. J Urol 1972, 108: $641-643$. colon were haemorrhagic with numerous diverticula. The patient recovered uneventfully.

\section{Discussion}

Fistulas of the umbilicus are rare and often represent a postoperative complication of abdominal surgery. ${ }^{2}$ A few case reports describe other novel aetiologies of umbilical fistulas, including: an omphalocyst, ${ }^{3}$ a patent urachus, ${ }^{4}$ and an umbilical hernia. ${ }^{5}$ Similarly, a utero-umbilical fistula has been documented following a cesarean section, ${ }^{6}$ and urinary obstruction has led to a vesicoumbilical fistula. ${ }^{7}$ Neurosurgical appliances such as a ventriculoperitoneal shunt can alsớ produce an umbilical fistula. ${ }^{8,9}$

Between $2.3 \%$ and $5.5 \%$ of entero-cutaneous fistulas are spontaneous; ${ }^{2,10,11}$ and only a small proportion of these would be of the enteroumbilical type. Spontaneous entero-umbilical fistulae have been associated anecdotally with Crohn's disease, ${ }^{1,11}$ tuberculosis peritonitis, ${ }^{12,13}$ and cholelithiasis leading to a spontaneous cholecystoumbilical fistula. ${ }^{14}$ In this report the fistula probably resulted from a perforation of a diverticulum at a point on the anterior abdominal wall where the sigmoid colon was adherent, preventing a generalized peritonitis with tracking of the fistula to the umbilicus along a line of what had been formerly the urachus. A large preperitoneal cavity and evidence of colonic obstruction made spontaneous closure of the fistula unlikely, and surgical management was recommended.

\section{Acknowledgements}

John B. Pracyk is a visiting fellow from the Medical Scientist Training Program, Duke University School of Medicine, and is supported by a grant from the Merck M.D., Ph.D. Academic Development Program.

8. Antunes, A.C. \& Riberio, T.R. Spontaneous umbilical fistula from ventriculoperitoneal shunt drainage. J Neurosurg 1975 , 43: 481-482.

9. Pompili, A. \& Cianfriglia, F. Umbilical fistula as a complication of ventriculoperitoneal shunt. Surg Neurol 1979, 12: $129-130$.

10. Coutsoftides, T. \& Fazio, V.W. Small intestine cutaneous fistulas. Surg Gynecol Obstet 1979, 149: 333-336.

11. Veloso, F.T., Cardoso, V., Frafa, J., Carvalho, J. \& Dias, L.M. Spontaneous umbilical fistula in Crohn's disease. J Clin Gastroenterol 1989, 11: 197-200.

12. Rao, P.L., Mitra, S.K. \& Pathak, J.C. Spontaneous tuberculous enteroumbilical fistulas. Am J Gastroenterol 1979, 72: 671-675.

13. Shscherba, B.V. \& Rogozov, L.I. Umbilical fistula in a patient with asymptomatic course of tuberculous peritonitis. Problemy Tuberkuleza 1988, 9: 70.

14. Davies, C.J. \& Fontaine, C.J. Spontaneous cholecystoumbilical fistula. Br J Radiol 1984, 57: 1034-1036. 